\title{
Crossing the Cervicothoracic Junction During Posterior Cervical Laminectomy and Fusion for The Treatment of Multilevel Cervical Ossification of The Posterior Longitudinal Ligament
}

\section{Dong-Zhao Wu}

The Third Hospital of Shijiazhuang

\section{Zhen-Fang Gu}

The Third Hospital of Shijiazhuang

De-Jing Meng

Shijiazhuang Emergency Center

\section{Shu-Bing Hou}

The Third Hospital of Shijiazhuang

\section{Liang Ren}

The Third Hospital of Shijiazhuang

Xian-Ze Sun ( $\nabla$ doctorsunxz@163.com )

The Third Hospital of Shijiazhuang

\section{Research Article}

Keywords: Ossification of the posterior longitudinal ligament, laminectomy, cervicothoracic, fusion

Posted Date: February 23rd, 2022

DOl: https://doi.org/10.21203/rs.3.rs-1095434/v1

License: (c) (i) This work is licensed under a Creative Commons Attribution 4.0 International License.

Read Full License 


\section{Abstract}

Purpose: The purpose of this study was to investigate the surgical efficacy of crossing the cervicothoracic junction during posterior cervical laminectomy and fusion for the treatment of multilevel cervical ossification of the posterior longitudinal ligament (OPLL).

Methods: From October 2009 to October 2017, 46 consecutive patients with multilevel cervical OPLL underwent posterior cervical laminectomy and crossing the cervicothoracic junction fusion were obtained in the study. Their medical records were retrospectively collected. Cervical lordosis and cervical sagittal balance were used to assess radiographic outcomes. Japanese Orthopedic Association (JOA), axial symptom, C5 root palsy, blood loss, and operation time were used to assess clinical outcomes. The mean follow-up period was $20.7 \pm 8.3$ months.

Results: The operation time was $205.2 \pm 39.8$ minutes and the intraoperative blood loss was $352.2 \pm$ $143.7 \mathrm{ml}$. Analysis of the final follow-up data showed significant differences in JOA score $(P<0.01), \mathrm{C} 2-\mathrm{C} 7$ lordosis angle $(\mathrm{P}<0.01)$, and $\mathrm{C} 2-\mathrm{C} 7 \mathrm{SVA}(\mathrm{P}<0.01)$. CT confirmed that grafted bone was completely fused in all patients and progression of OPLL was observed in two patients(4.3\%) at final follow-up. No adjacent segment disease (ASD) or instrument failure occurred in any patients.

Conclusions: Cervical laminectomy and crossing the cervicothoracic junction fusion are effective and safe methods to treat multilevel cervical OPLL. Randomized controlled studies with long-term follow-up are needed to confirm these results.

\section{Introduction}

Ossification of the posterior longitudinal ligament (OPLL) is attributed to heterotopic ossification of the cervical or thoracic PLL, potentially leading to spinal cord compression and neurologic deterioration.[1, 2] At a mean follow-up of 17.6 years, only $17 \%$ of 323 patients without myelopathy evident at the first examination developed myelopathy.[3] So it's neither necessary nor recommended to perform prophylactic surgery.[1] However, in patients with myelopathy evident at the first examination who underwent conservative therapy, $64 \%$ had deteriorated and $89 \%$ of patients with Nurick grade 3 or 4 myelopathy managed conservatively became completely disabled.[3] In addition, Cervical spinal cord injury and related disability are more likely to occur in OPLL patients.[4] For these reasons, surgical decompression is considered in patients with progressive myelopathy.

Surgical options include anterior corpectomy and fusion, laminoplasty, and laminectomy and fusion.[7] All surgical methods have advantages and disadvantages. Currently the optimal surgical treatment of cervical myelopathy caused by OPLL remains controversial. The purpose of this retrospective study was to evaluate the surgical efficacy of crossing the cervicothoracic junction during posterior cervical laminectomy and fusion for the treatment of multilevel cervical OPLL.

\section{Methods}




\section{Patients}

From October 2009 to October 2017, 46 consecutive patients (38 males, 8 females; mean age $55.4 \pm 7.4$ years) with multilevel cervical OPLL underwent posterior cervical laminectomy and crossing the cervicothoracic junction fusion were obtained in the study. Their medical records were retrospectively collected. Patient inclusion criteria were (1) radiographic confirmation of cervical OPLL, (2) compressive lesion more than 3 cervical levels, and (3) clearly documented progressive cervical myelopathy. Exclusion criteria were (1) fractures, tumors, and metabolic disorders, (2) only axial neck pain without myelopathy, (3) concurrent anterior cervical spine procedures, and (4) prior surgery of the cervical spine.

\section{Operative Technique}

In our center, all spinal surgeries were performed under monitoring of transcranial motor-evoked potentials, somatosensory-evoked potentials, and free-running electromyography. The patients were placed in the prone position after general anesthesia. A standard posterior midline exposure was performed for all procedures. The paravertebral muscles were retracted laterally and muscle insertion of $\mathrm{C} 2$ spinous process was retained. Then, $\mathrm{C} 2$ was implanted pars screws. Lateral mass screws were placed from $\mathrm{C} 3$ to $\mathrm{C} 5$. Pedicle screws were placed in $\mathrm{C} 7$ and T1. We did not implant screws in $\mathrm{C} 6$ to facilitate installation of connecting rods. Subsequently, A dome-shaped sublaminar decompression was performed at C2 with a high-speed burr. From C3 to C7, a full-thickness trough was drilled at the junction of the lateral mass and the lamina with a high-speed burr. The laminae were elevated from the one side toward the other side and were removed completely. Then, enlarged laminectomy was performed to ensure adequate decompression which including adequate decompression of neural foramina and the removal of the inside edges of facet joints. Finally, posterolateral bone grafting at the fixation region was performed. Postoperatively, patients were required to stay in bed for 3-5 days and thereafter walking was allowed with a cervical collar for one month.

\section{Radiologic and clinical evaluation}

Radiographs, computerized tomography (CT), and clinical evaluation was performed preoperatively and at the final follow-up. Type of the OPLL was classified as localized, segmental, continuous or mixed morphology basing on the sagittal CT images. The cervical sagittal balance was measured by C2-C7 lordosis and C2-C7 sagittal vertical axis (SVA) as shown in Fig 1. C2-C7 lordosis was defined as the sagittal Cobb angle between C2 and C7 vertebral bodies. C2-C7 SVA was defined as the distance between C2 plumbline and C7. OPLL progression was measured by length and depth growth.[5] A threedimensional CT scan was performed to confirm fusion and OPLL progression. Progression of OPLL was defined as an increased ossification of $\geq 2 \mathrm{~mm}$ in length or thickness.[20] Kyphosis line (K-line) was defined as a line connecting the center of the canal at $\mathrm{C} 2$ to the center at $\mathrm{C} 7$ on neutral radiographs. The K-line (-) was defined when the OPLL exceeded the K-line and K-line $(+)$ was defined when the OPLL did not exceed the K-line. The OPLL occupying ratio (OR) was defined as the biggest ratio of OPLL thickness to antero-posterior diameter of the bony spinal canal on the axial CT image. All radiological evaluations were performed by an independent surgeon who was not involved in patient treatment. 
Clinical outcome was measured by Japanese Orthopedic Association (JOA) scoring system. The neurological recovery rate was calculated as (postoperative JOA score-preoperative score)/(17preoperative score) $* 100 \%$. Recovery rates were graded as follows: $75 \%$ and greater, excellent; $50 \%$ to $74 \%$, good; $25 \%$ to $49 \%$, fair; and less than $25 \%$, poor.[6] Blood loss, operation time, and complications were reviewed for each case.

\section{Statistical analysis}

We used the SPSS statistical package (version 21.0; SPSS Inc, Chicago, IL, USA) for data analysis. P< 0.05 was considered significant. A paired $t$ test was used to assess statistical significance of changes between postoperative and preoperative parameters in each group.

\section{Results}

\section{Patient characteristics}

Posterior cervical laminectomy and crossing the cervicothoracic junction fusion were performed in all patients. The patient characteristics were summarized in Table 1. The mean symptomatic duration was $34.9 \pm 12.3$ months. In total, 5 patients $(10.9 \%)$ had segmental OPLL, 27 patients $(58.7 \%)$ had continuous OPLL and 14 patients (30.4\%) had mixed OPLL. Imaging study showed that 12 patients with highintensity signal on T2WI-MRI, 10 patients with occupying ratio of OPLL $\geq 60 \%$, and 15 patients with K-line (-). Surgical extent was from C2 to T1 in all patients. The average follow-up period was $20.7 \pm 8.3$ months. The average operation time was $205.2 \pm 39.8$ minutes (range 120-300 minutes) with a mean intraoperative blood loss of $352.2 \pm 143.7 \mathrm{ml}$ (range 150-800 ml).

\section{Neurological results}

The JOA scores had significantly improved from preoperative $8.0 \pm 2.0$ to $13.8 \pm 1.8$ at final followup $(p<0.01)$. ( Table 2 ) The average neurological recovery rate was $65.6 \pm 14.2 \%$. Neurological recovery rates were excellent in 16 (34.8\%) patients, good in 25 (54.3\%) patients, fair in 5 (10.9\%) patients, and poor in $0(0 \%)$ patients.

\section{Radiological results}

X-ray radiographs showed that $\mathrm{C} 2-\mathrm{C} 7$ lordosis angle had significantly increased from $6.0 \pm 3.1^{\circ}$ preoperatively to $9.5 \pm 3.0$ at final follow-up $(p<0.01)$ and C2-C7 SVA had significantly decreased from $26.7 \pm 4.9$ preoperatively to $9.5 \pm 3.0$ at final follow-up $(p<0.01)$. CT confirmed that grafted bone was completely fused in all patients and progression of OPLL was observed in two patients (4.3\%) at final follow-up.(Fig 2)

\section{Complications}


Complications included axial symptoms in three cases (6.5\%). The patients with axial symptoms needed to take nonsteroidal antiinflammatory drugs orally and all relieved after 3 months. There was no C5 root palsy, adjacent segment disease and instrument failure occurred during the follow-up.

\section{Discussion}

The optimal surgical treatment option for multilevel cervical OPLL remains controversial. Surgical options include anterior corpectomy and fusion, laminoplasty, and laminectomy and fusion.[7]

Anterior corpectomy and fusion allows for direct removal of the OPLL mass and is more effective at restoring cervical lordosis than posterior surgery.[1] However, disadvantages of anterior approach are technical difficulty and high complication rates which include pseudarthrosis, dysphagia, and dural tears.[7] So the posterior approaches are preferable with more than three levels involved.[8]

The common posterior approaches, laminoplasty and laminectomy and fusion, use an indirect decompression with less technically demanding and lower rate of complications.[9]

Laminoplasty accomplishes decompression by hinging open the laminae and results in a $30 \%$ to $40 \%$ increase in the size of canal volume.[10] Compared with laminectomy and fusion, Laminoplasty is advocated because of its preservation of neck range of motion (ROM). [7]

However, neck ROM may incite further progression of OPLL. Progression of the ossification was found in $66 \%$ of the patients underwent laminoplasty.[11] According to Yoshida, limiting cervical ROM may prevent late deterioration due to progression of OPLL.[12] Morio reported that restriction of segmental motion was associated with clinical improvement in myelopathy.[13]

In addition, complications associated with laminoplasty include closure of the opened lamina, hinge fracture, development of postoperative malalignment.[9] Significant kyphosis and instability are contraindications for laminoplasty.[14]

So laminectomy and fusion may be preferred for the treatment of multilevel cervical OPLL. Laminectomy and fusion removes the laminae followed by instrumented fusion and results in a $70 \%$ to $80 \%$ increase in spinal canal.[10] According to Houten, laminectomy and posterior lateral mass fusion can lead to high rates of fusion, preserved lordosis, and clinical results comparable or superior to those seen with anterior surgery.[15]

A significant portion of laminectomy requires posterior fusions caudally to $\mathrm{C} 6$ or $\mathrm{C} 7$. However, cervicothoracic junction is a transition point between the lordosis of the cervical spine and the kyphosis of the thoracic spine. Furthermore, the subaxial cervical spine provides up to $20^{\circ}$ of combined flexion/extension, $10^{\circ}$ of lateral bending, and $5^{\circ}$ to $7^{\circ}$ of rotation per level. This mobility is in stark contrast to the structurally rigid thoracic spine, which permits $<5^{\circ}$ of flexion/extension and lateral bending per level. The substantial difference between mobility in cervical and thoracic spine may amplify rates of 
adjacent segment disease at the cervicothoracic junction when multilevel cervical fusions are terminated in the lower cervical spine.[16, 17]

So, routine extension of posterior cervical fusions into the thoracic spine has been suggested. The benefits of extension into the thoracic spine include greater surface area for the fusion mass and the larger screws typically employed in the thoracic spine which may offer greater construct rigidity and a more stable mechanical environment.[18]

According to Osterhoff et al, secondary interventions due to adjacent segmental pathology or implant failure were necessary in 18/58 (31.8\%) of the C7-cases and in 1/16 (6.3\%) of the T1/2-cases ( $p=0.038)$. So, they suggested that patients with multi-segmental posterior cervical fusions ending at $\mathrm{C} 7$ showed a higher rate of clinically symptomatic pathologies at the adjacent level below the instrumentation. One may consider to bridge the cervico-thoracic junction and to end the instrumentation at T1 or T2 in those cases.[19]

As Schroeder et al presented, a significant difference in the revision rates was identified between fusions

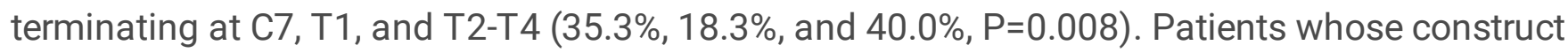
terminated at $\mathrm{C} 7$ were $2.29(1.16-4.61)$ times more likely to require a revision than patients whose construct terminated at T1 $(\mathrm{P}=0.02)$, but no difference between stopping at T1 and T2-T4 was identified. So, they recommended that multilevel posterior cervical fusions should be extended to T1, as stopping a long construct at $\mathrm{C} 7$ increases the rate of revision.[16]

In our study, grafted bone was completely fused in all patients. There was no adjacent segment disease and instrument failure occurred during the follow-up.

Progression of OPLL could be observed both during the natural course and after surgery. The incidence of postoperative progression reported in the literature varied from 3.3\% to 74.5\%.[20] As Sakai K et al presented, postoperative progression of OPLL was observed in $5 \%$ of the anterior decompression and fusion with floating method group and $50 \%$ of the laminoplasty group.[21] Lee et al reported that the incidence progression of OPLL was $45.5 \%, 62.5 \%$, and $30 \%$ for laminoplasty, laminectomy, and laminectomy with fusion, respectively.[22] Lee et al performed a meta-analysis of 11 studies and reported a $62.5 \%$ incidence of OPLL progression after laminoplasty and $7.6 \%$ after anterior or posterior fusion surgery.[23] So, posterior decompression with instrumented fusion surgery could suppress the progression of OPLL.[20] In our study, progression of OPLL was observed in two patients(4.3\%) at final follow-up.

C5 palsy is a serious complication after cervical decompression surgery in which the patient shows deterioration in power of the deltoid or biceps brachii. According to Pan FM et al, the average incidence rate of $\mathrm{C} 5$ palsy after posterior cervical spine surgery was $7.8 \%$ (range, 1.4-23.0\%). Risk factors for C5 palsy included age, male gender, OPLL, and stenosis of the C4-C5 intervertebral foramen.[24] Foraminotomy and intraoperative neuromonitoring were the two main methods used to prevent $\mathrm{C} 5$ palsy. In our study, both foraminotomy and intraoperative neuromonitoring was used to prevent C5 palsy. 
Axial symptoms are defined as pain from the nuchal to the periscapular or shoulder region. According to Wang $\mathrm{M}$ et al, The pooled axial symptoms prevalence was $28 \%(95 \% \mathrm{Cl} 24-32)$. The prevalence of axial symptoms was higher after expansive open-door laminoplasty (39\%) than after modified open-door laminoplasty (23\%) and laminectomy instrumented fusion (29\%). They suggested that postoperative axial symptoms may be reduced through preserving posterior muscles and structures, stabilizing cervical vertebrae, and reducing external cervical immobilization time.[25] The semispinalis cervicis, most of which inserts on $\mathrm{C2}$, acts as a dynamic stabilizer and extensor of the cervical spine.[26] For complete preservation of the semispinalis cervicis inserted in $\mathrm{C} 2$, Takeuchi et al changed the laminoplastic procedure from C3-C7 laminoplasty to C4-C7 laminoplasty with C3 laminectomy. Their report demonstrated that modified laminoplasty with preservation of the semispinalis cervicis significantly reduced postoperative axial symptoms.[27] In our study, muscle insertion of C2 spinous process was retained and cervical collar was worn for one month, which were performed to prevent axial symptoms.

C2-C7 lordosis angle and C2-C7 SVA were used to measure the translation of cervical spine in the sagittal plane.[28] Lee et al reported expansive laminoplasty vs laminectomy alone vs laminectomy and fusion for cervical OPLL. Cervical lordosis, C2-C7 Cobb angle and CCl, decreased gradually in all patients. SVA was maintained in laminectomy and fusion group only and increased in the others.[22] According to Liu $X$ et al, the SVA significantly increased in expansive open-door laminoplasty and was maintained in laminectomy and instrumented fusion for cases with cervical OPLL. C2-C7 Cobb angle increased in laminectomy and instrumented fusion and decreased in expansive open-door laminoplasty.[29] Our results showed that C2-C7 Cobb angle increased and C2-C7 SVA decreased, which was similar with the result of Liu $\mathrm{X}$ et al.

JOA was used to evaluate neurological recovery. Excellent neurological recovery is associated with the extent of decompression. Extensive laminectomy, as an alternative surgical option, allowed adequate decompression of the spinal cord and nerve roots by removing spinous processes, lamina, ligamentum flavum, and especially the inner less than $1 / 4$ of facet joints on each side.[30] According to Du W et al, enlarged laminectomy with fixation for the management of multilevel cervical degenerative myelopathy was demonstrated to be an effective strategy for improving neurological function. We performed enlarged laminectomy in patients with multilevel cervical OPLL and excellent neurological recovery was obtained.

There are several limitations in this study. Firstly, it is a retrospective, single-institution study. Then, there is no control group and sample size is small. Finally, follow-up time is insufficient. So, randomized controlled studies with long-term follow-up are needed to confirm these results.

\section{Conclusion}

Cervical laminectomy and crossing the cervicothoracic junction fusion for treatment of multilevel cervical OPLL is demonstrated to be an effective strategy for improving neurological function, decreasing the incidence of adjacent segment disease and instrument failure, restoring cervical lordosis, preventing 
progression of OPLL. Randomized controlled studies with long-term follow-up are needed to confirm these results.

\section{Abbreviations}

OPLL: ossification of the posterior longitudinal ligament; SVA: sagittal vertical axis; JOA: Japanese Orthopedic Association; SD: standard deviation; OR: occupying ratio; ASD: adjacent segment disease

\section{Declarations}

\section{Ethics approval and consent to participate}

This study was approved by the institutional review board of The Third Hospital of Shijiazhuang. All the patients in this study provided with written, informed consent prior to participation.

\section{Consent for publication}

All authors agree to the publication of this article

\section{Competing interests}

The authors declare that they have no competing interests.

\section{Funding}

No funds were received in support of this work.

\section{Authors' contributions}

All authors have read and approved the manuscript. Dong-Zhao Wu: The frst author, surgeon of this series. Xian-Ze Sun: The corresponding author, main surgeon of this series. Zhen-Fang Gu, Shu-Bing Hou, and Liang Ren: The surgeons of this series. De-Jing Meng was involved in study design and data interpretation.

\section{Acknowledgements}

The authors are grateful to Dr. Fengyu Liu for editing a draft of this manuscript.

\section{References}

1. An HS, Al-Shihabi L, Kurd M. Surgical treatment for ossification of the posterior longitudinal ligament in the cervical spine. J Am Acad Orthop Surg. 2014 Jul;22(7):420-429.

2. Smith ZA, Buchanan CC, Raphael D, Khoo LT. Ossification of the posterior longitudinal ligament: pathogenesis, management, and current surgical approaches. A review. Neurosurg Focus. 2011 
Mar;30(3):E10.

3. Matsunaga S, Sakou T, Taketomi E, Komiya S. Clinical course of patients with ossification of the posterior longitudinal ligament: a minimum 10-year cohort study. J Neurosurg. 2004 Mar;100(3 Suppl Spine):245-8.

4. Wu JC, Chen YC, Liu L, Huang WC, Chen TJ, Lo SS, Thien PF, Cheng H. Conservatively treated ossification of the posterior longitudinal ligament increases the risk of spinal cord injury: a nationwide cohort study. J Neurotrauma. 2012 Feb 10;29(3):462-8.

5. Epstein N. Ossification of the cervical posterior longitudinal ligament: a review. Neurosurg Focus. 2002 Aug 15;13(2):ECP1.

6. Du W, Zhang P, Shen Y, Zhang YZ, Ding WY, Ren LX. Enlarged laminectomy and lateral mass screw fixation for multilevel cervical degenerative myelopathy associated with kyphosis. Spine J. 2014 Jan;14(1):57-64.

7. Singhatanadgige W, Limthongkul W, Valone F 3rd, Yingsakmongkol W, Riew KD. Outcomes following Laminoplasty or Laminectomy and Fusion in Patients with Myelopathy Caused by Ossification of the Posterior Longitudinal Ligament: A Systematic Review. Global Spine J. 2016 Nov;6(7):702-709.

8. Yuan W, Zhu Y, Liu X, Zhu H, Zhou X, Zhou R, Cui C, Li J. Postoperative three-dimensional cervical range of motion and neurological outcomes in patients with cervical ossification of the posterior longitudinal ligament: Cervical laminoplasty versus laminectomy with fusion. Clin Neurol Neurosurg. 2015 Jul;134:17-23.

9. Matsumoto M, Chiba K, Toyama Y. Surgical treatment of ossification of the posterior longitudinal ligament and its outcomes: posterior surgery by laminoplasty. Spine (Phila Pa 1976). 2012 Mar 1;37(5):E303-8.

10. Manzano GR, Casella G, Wang MY, Vanni S, Levi AD. A prospective, randomized trial comparing expansile cervical laminoplasty and cervical laminectomy and fusion for multilevel cervical myelopathy. Neurosurgery. 2012 Feb;70(2):264-77.

11. Chiba K, Ogawa Y, Ishii K, Takaishi H, Nakamura M, Maruiwa H, Matsumoto M, Toyama Y. Long-term results of expansive open-door laminoplasty for cervical myelopathy-average 14-year follow-up study. Spine (Phila Pa 1976). 2006 Dec 15;31(26):2998-3005.

12. Yoshida M, Otani K, Shibasaki K, Ueda S. Expansive laminoplasty with reattachment of spinous process and extensor musculature for cervical myelopathy. Spine (Phila Pa 1976). 1992 May;17(5):491-7.

13. Morio Y, Yamamoto K, Teshima R, Nagashima H, Hagino H. Clinicoradiologic study of cervical laminoplasty with posterolateral fusion or bone graft. Spine (Phila Pa 1976). 2000 Jan 15;25(2):1906.

14. Yoon ST, Hashimoto RE, Raich A, Shaffrey Cl, Rhee JM, Riew KD. Outcomes after laminoplasty compared with laminectomy and fusion in patients with cervical myelopathy: a systematic review. Spine (Phila Pa 1976). 2013 Oct 15;38(22 Suppl 1):S183-94. 
15. Houten JK, Cooper PR. Laminectomy and posterior cervical plating for multilevel cervical spondylotic myelopathy and ossification of the posterior longitudinal ligament: effects on cervical alignment, spinal cord compression, and neurological outcome. Neurosurgery. 2003 May;52(5):1081-7; discussion 1087-8.

16. Schroeder GD, Kepler CK, Kurd MF, Mead L, Millhouse PW, Kumar P, Nicholson K, Stawicki C, Helber A, Fasciano D, Patel AA, Woods BI, Radcliff KE, Rihn JA, Anderson DG, Hilibrand AS, Vaccaro AR. Is It Necessary to Extend a Multilevel Posterior Cervical Decompression and Fusion to the Upper Thoracic Spine? Spine (Phila Pa 1976). 2016 Dec 1;41(23):1845-1849.

17. Fayed I, Toscano DT, Triano MJ, Makariou E, Lee C, Spitz SM, Anaizi AN, Nair MN, Sandhu FA, Voyadzis JM. Crossing the Cervicothoracic Junction During Posterior Cervical Decompression and Fusion: Is It Necessary? Neurosurgery. 2020 Jun 1;86(6):E544-E550.

18. Truumees E, Singh D, Geck MJ, Stokes JK. Should long-segment cervical fusions be routinely carried into the thoracic spine? A multicenter analysis. Spine J. 2018 May;18(5):782-787.

19. Osterhoff G, Ryang YM, von Oelhafen J, Meyer B, Ringel F. Posterior Multilevel Instrumentation of the Lower Cervical Spine: Is Bridging the Cervicothoracic Junction Necessary? World Neurosurg. 2017 Jul;103:419-423.

20. Fayed I, Toscano DT, Triano MJ, Makariou E, Lee C, Spitz SM, Anaizi AN, Nair MN, Sandhu FA, Voyadzis JM. Crossing the Cervicothoracic Junction During Posterior Cervical Decompression and Fusion: Is It Necessary? Neurosurgery. 2020 Jun 1;86(6):E544-E550.

21. Wang L, Jiang Y, Li M, Qi L. Postoperative Progression of Cervical Ossification of Posterior Longitudinal Ligament: A Systematic Review. World Neurosurg. 2019 Jun;126:593-600.

22. Sakai K, Okawa A, Takahashi M, Arai Y, Kawabata S, Enomoto M, Kato T, Hirai T, Shinomiya K. Fiveyear follow-up evaluation of surgical treatment for cervical myelopathy caused by ossification of the posterior longitudinal ligament: a prospective comparative study of anterior decompression and fusion with floating method versus laminoplasty. Spine (Phila Pa 1976). 2012 Mar 1;37(5):367-76.

23. Lee CH, Jahng TA, Hyun SJ, Kim KJ, Kim HJ. Expansive Laminoplasty Versus Laminectomy Alone Versus Laminectomy and Fusion for Cervical Ossification of the Posterior Longitudinal Ligament: Is There a Difference in the Clinical Outcome and Sagittal Alignment? Clin Spine Surg. 2016 Feb;29(1):E9-15.

24. Lee CH, Sohn MJ, Lee CH, Choi CY, Han SR, Choi BW. Are There Differences in the Progression of Ossification of the Posterior Longitudinal Ligament Following Laminoplasty Versus Fusion?: A MetaAnalysis. Spine (Phila Pa 1976). 2017 Jun 15;42(12):887-894.

25. Pan FM, Wang SJ, Ma B, Wu DS. C5 nerve root palsy after posterior cervical spine surgery. J Orthop Surg (Hong Kong). 2017 Jan;25(1):2309499016684502.

26. Wang M, Luo XJ, Deng QX, Li JH, Wang N. Prevalence of axial symptoms after posterior cervical decompression: a meta-analysis. Eur Spine J. 2016 Jul;25(7):2302-10. doi: 10.1007/s00586-0164524-2. Epub 2016 Mar 19. Erratum in: Eur Spine J. 2016 Jun;25(6):1968. 
27. Takeuchi K, Yokoyama T. Comparison of Axial Symptoms and Limitations of Activities of Daily Living Accompanying Reduced Neck Mobility After Cervical Laminoplasty Preserving C2 Muscle Attachments With and Without C2 to T1 Instrumented Fusion. Neurospine. 2019 Sep;16(3):608-617.

28. Takeuchi K, Yokoyama T, Aburakawa S, Saito A, Numasawa T, Iwasaki T, Itabashi T, Okada A, Ito J, Ueyama K, Toh S. Axial symptoms after cervical laminoplasty with C3 laminectomy compared with conventional C3-C7 laminoplasty: a modified laminoplasty preserving the semispinalis cervicis inserted into axis. Spine (Phila Pa 1976). 2005 Nov 15;30(22):2544-9.

29. Scheer JK, Tang JA, Smith JS, Acosta FL Jr, Protopsaltis TS, Blondel B, Bess S, Shaffrey Cl, Deviren V, Lafage V, Schwab F, Ames CP; International Spine Study Group. Cervical spine alignment, sagittal deformity, and clinical implications: a review. J Neurosurg Spine. 2013 Aug;19(2):141-59.

30. Liu X, Chen Y, Yang H, Li T, Xu B, Chen D. Expansive open-door laminoplasty versus laminectomy and instrumented fusion for cases with cervical ossification of the posterior longitudinal ligament and straight lordosis. Eur Spine J. 2017 Apr;26(4):1173-1180.

31. Li Z, Xue Y, He D, Tang Y, Ding H, Wang Y, Zong Y, Zhao Y. Extensive laminectomy for multilevel cervical stenosis with ligamentum flavum hypertrophy: more than 10 years follow-up. Eur Spine J. 2015 Aug;24(8):1605-12.

\section{Tables}

Table 1 Patient characteristics 


\begin{tabular}{|ll|}
\hline Characteristics & Value \\
\hline Number of patients & 46 \\
\hline Age (years) & $55.4 \pm 7.4$ \\
\hline Gender & \\
\hline Male & 38 \\
\hline Female & 8 \\
\hline Symptomatic duration (months) & $34.9 \pm 12.3$ \\
\hline High-intensity signal on T2WI-MRI & 12 \\
\hline Type of OPLL & \\
\hline Local & 0 \\
\hline Segmental & 5 \\
\hline Continuous & 27 \\
\hline Mixed & 14 \\
\hline Occupying ratio of OPLL & \\
\hline$\square 60 \%$ & 36 \\
\hline$\geq 60 \%$ & 10 \\
\hline K-line & $20.7 \pm 8.3$ \\
\hline (+) & $205.2 \pm 39.8$ \\
\hline$(-)$ & $352.2 \pm 143.7$ \\
\hline Follow-up (month) & 15 \\
\hline Operation time (minute) & \\
\hline Blood loss (ml) & \\
\hline
\end{tabular}

OPLL: ossification of the posterior longitudinal ligament

Table 2 Summary of clinical and radiologic outcomes 


\begin{tabular}{|llll|}
\hline $\mathrm{n}=46$ & Preoperative & Final & $\mathrm{P}$ \\
\hline JOA score & $8.0 \pm 2.0$ & $13.8 \pm 1.8$ & $<0.01$ \\
\hline C2-C7 lordosis angle $\left(^{\circ}\right)$ & $6.0 \pm 3.1$ & $9.5 \pm 3.0$ & $<0.01$ \\
\hline C2-C7 SVA $(\mathrm{mm})$ & $26.7 \pm 4.9$ & $25.4 \pm 4.3$ & $<0.01$ \\
\hline
\end{tabular}

\section{Figures}

\section{Figure 1}

The evaluation of the $\mathrm{C} 2-\mathrm{C} 7 \mathrm{Cobb}$ angle and the SVA.

\section{Figure 2}

A 63-year-old male patient with multilevel, mixed-type ossification of the posterior longitudinal ligament. Preoperative computed tomography scan showed ossification of the posterior longitudinal ligament involving C2-T1 (a). Preoperative magnetic resonance image showed the pathological extent involving 6 intervertebral levels (b). He accepted crossing the cervicothoracic junction fusion from C2 to T1 and acquired sufficient decompression from $\mathrm{C} 2$ to $\mathrm{C} 7$ (c, d). Computed tomography scan of 12 month after surgery showed progression of ossification of the posterior longitudinal ligament (e). Computed tomography scan of 12 month after surgery showed fusion in the facet joints (f). 